\title{
ISRAEL GALVÁN EN LA FIESTA: SU BAILE FLAMENCO CONTEMPORÁNEO Y TRANSGRESOR DE LA TEATRALIZACIÓN
}

\section{María Cabrera Fructuoso}

Investigadora independiente

\section{Resumen}

En el siguiente artículo nos proponemos profundizar en el estudio del baile flamenco de la teatralización actual, en sus movimientos, sus sonidos y sus espectáculos, tomando como modelo al artista Israel Galván y, en concreto, su obra La Fiesta. Todo ello contextualizado en la era de la globalización, teniendo en cuenta sus flujos culturales y su consecuente hibridación, transculturación y transgresión en el arte.

Palabras clave: BAILE FLAMENCO; GALVÁN, ISRAEL (1973-); TEATRALIZACIÓN; TRANSGRESIÓN; GLOBALIZACIÓN

\section{ISRAEL GALVÁN IN LA FIESTA: HIS CONTEMPORARY AND TRANSGRESSIVE FLAMENCO DANCE}

\section{Abstract}

In the following article we propose to go into detail about the study of the flamenco dance in the current theatricalisation, in its movements, its sounds and its performances, taking as a model the artist Israel Galván and, specifically, his work La Fiesta. All of this contextualised in the era of globalisation, taking into account its cultural flows and its consequent hybridisation, transculturation and transgression in art.

Key words: FLAMENCO DANCE; GALVÁN, ISRAEL (1973-); THEATRICALISATION; TRANSGRESSION; GLOBALIZATION

\footnotetext{
Cabrera Fructuoso, María. 2021. "Israel Galván en La Fiesta: Su baile

flamenco contemporáneo y transgresor de la teatralización". AusArt

9 (1): 211-222. DOI: 10.1387/ausart.22603
} 


\section{INTRODUCCIÓN}

La música, la danza y el arte en general se encuentran determinados socialmente, en parte, porque surgen y se desarrollan de forma activa en una sociedad concreta, debido a su capacidad cognitiva, semántica y de creación de elementos por medio de la comunicación, el divertimento y la transformación de emociones.

Enmarcándonos dentro del contexto de la globalización, que implica un proceso de conexión e intercambio activo, tiene lugar una disminución de las barreras, a la vez que aparece una necesidad de búsqueda de identidad y donde el concepto de 'lo local' se ve redefinido y renovado. De manera que "la confrontación con lo extraño se convierte en una potencia culturizadora" (Erdheim en Steingress 2004, 12).

Asimismo, los flujos culturales se han visto incrementados y acelerados gracias a la apertura de los mercados, los medios de comunicación, los avances tecnológicos y de transporte, -favoreciendo desplazamientos y migraciones por parte de los artistas y estudiantes, potenciando la transmisión y difusión de su arte, conllevando, a su vez, una mayor interculturalidad, pluriculturalidad y multiculturalidad- (Steingress 2004).

Aparece de esta forma el concepto 'hibridación' en el arte y, por supuesto, también en el flamenco, al sucederse tal grado de fusión que se origina un estilo nuevo con su público, producción, marketing, etc. Así, "da respuesta a unas necesidades subyacentes y se convierte en un producto que garantiza su expansión y difusión" (Cabrera 2019, 141), donde la obra o espectáculo se convierte en producto y, con ello, aparece la obligatoriedad y la necesidad de revalorizar su inversión, -de ahí que el artista en numerosas ocasiones se vea limitado o influenciado por la industria y el mercado artístico-.

De manera que, el flamenco contemporáneo, en cuanto a coetáneo, aparecería como una manifestación artística sociocultural inmersa en los flujos de la globalización y su consecuente "hibridación transcultural", pues implica "la transgresión del marco de las culturas nacionales y/o étnicas con la innovación y creación de nuevas manifestaciones artístico-estéticas" (Steingress 2004, 4).

Asimismo, la hibridación también implicaría vitalidad, liberalización y transgresión artístico-creadora. En el campo musical flamenco aparecería en torno a 
los años setenta con el fenómeno de 'Flamenco fusión' o ‘Fusión flamenca' de la mano de artistas como Camarón de la Isla, El Lebrijano, Enrique Morente o Paco de Lucía. La utilización del concepto 'fusión' se utilizaría para referirse a la mezcla de diferentes elementos o géneros musicales, ocurriendo esto por primera vez en el disco Rock Encounter de Joe Beck y Sabicas (1966).

Esta corriente daría lugar a la aparición a partir de los años ochenta del 'Nuevo flamenco', término creado por la compañía Nuevos Medios y Flamencos Accidentales (subsello de GASA), potenciado por acontecimientos como la movida madrileña o la apertura artística que conllevó la finalización del régimen franquista, y cuyo propósito era el de desligarse del modelo mairenista de 1955.

De esta manera surgiría una nueva corriente ecléctica y heterogénea que, a través de un lenguaje híbrido e innovador relacionado con el flamenco en mayor o menor medida dependiendo del artista o grupo musical, originaría un nuevo producto musical y comercial (Ketama, Pata Negra, Tomatito o O'FunkiIlo). Asimismo, en esta generación encontraríamos el concepto del que habla el etnomusicólogo Mantle Hood de 'bi-musicalidad', es decir, que el músico posee un conocimiento y formación intrínsecos de diversos estilos permitiendo hibridarlos de una forma completamente natural.

En el ámbito dancístico flamenco, por su parte, también encontramos el fenómeno de 'bi-dancístico' gracias a la profundización de artistas de esta disciplina en la danza contemporánea, principalmente, como se puede observar en Rocío Molina, Belén Maya, Israel Galván, Eva Yerbabuena, Olga Pericet, María Pagés, Jesús Carmona, Daniel Doña o Sara Cano. Aunque este fenómeno no sería nuevo, pues ya con Mariemma, Antonio Ruiz o Antonio Gades se comenzó a tomar la danza clásica como una herramienta base para la formación de los bailarines/bailaores.

No obstante, no solo tiene lugar esa interrelación entre distintas danzas, sino que va más allá encontrando a artistas flamencos colaborando y trabajando de la mano junto con otros de diferentes gremios artísticos en pro del mensaje y de la obra, como ya sucedía con generaciones anteriores.

Además, aparece una necesidad de experimentación con el espacio y su proximidad con el público. Esto conlleva que se lleven a cabo piezas y obras para ser interpretadas en espacios no convencionales al baile flamenco, como Impulsos (2016) de Rocío Molina o las piezas de videoarte Mimético y En cualquier parte (2016) de Eduardo Guerrero junto a Félix Vázquez. 
Asimismo, el creciente progreso industrial y tecnológico que ha tenido lugar en las ciudades, también ha servido de inspiración para artistas como Vicente Escudero, quien creará su pieza El baile de los motores (1928). Pero también el componente técnico y de innovación ha servido de inspiración en espectáculos como Utopía de María Pagés (2011) donde, inspirada en la obra del arquitecto Oscar Niemeyer y su concepto de la curva, creó una escenografía modulante maravillosa y cuyo mensaje surge de la necesidad de crear un espacio o mundo mejor, donde se recuperen los valores y prevalezca la ética sobre la estética, potenciado no sólo por la escenografía, sino por el resto de elementos deícticos dotados de gran significación (vestuario, iluminación, color, música, movimiento...).

La danza y la música requieren y necesitan de un lugar que facilite su materialización y consumo. Encontramos así al urbanismo como ese espacio de creación, inspiración y convivencia para el arte, incorporándolo en su contenido. Como expresa Theodore Zeldin (1997), los artistas son mediadores a través de la expresión de emociones, pues gracias a "la peculiar consistencia de la música, sin contornos precisos, hace de ella, un perfecto catalizador de sentimientos colectivos" (Martínez 2008, 9).

Por lo que, la ciudad es entendida como un compendio de tiempo, espacio, sonidos y movimientos que se necesitan entre sí. Como imaginarios que, por medio de lo cotidiano, generan diferentes discursos, pues desde el punto de vista de la sociología "comparten un flujo ininterrumpido de identidades e identificaciones mutuas. La globalización aproxima sus contenidos y dependencias, en la medida en que el espacio, en el sentido físico y social aspira a la condición evanescente de este privilegio" (Menéndez en García Peinazo 2013 , 8). De manera que cualquier modificación afecta e influye en el arte, la sociedad, sus significaciones y valores. El arte aparece como un ejercicio por y para la ciudadanía.

\section{ISRAEL GALVÁN COMO ARTISTA CREADOR E INTÉRPRETE DEL BAILE FLAMENCO DE LA TEATRALIZACIÓN}

Para entender en qué consiste la teatralización del baile flamenco, hay que situarnos en torno a 1847-1915 cuando tiene lugar la evolución de lo profesio- 
nal a lo escénico, tras estrenarse El amor brujo de Pastora Imperio, bajo el subtítulo de Gitanerías, en el Teatro Lara. Obra clave dentro del repertorio de la danza española y el flamenco, siendo interpretada y versionada por numerosos artistas.

Asimismo, tomando a Ramiro Guerra (1989), la teatralización estaría compuesta de diferentes estadios o niveles de complejidad, siendo el cuarto y último el de la creación artística. Aquí encontramos al artista que toma su propia tradición dancística, retomándola, recreándola, sirviéndose e inspirándose en ella para crear, según su capacidad artística y talento, y reinventarla sin extraviarse en un uso y abuso.

Por lo que, enmarcándonos dentro del período teatralizado contemporáneo, nos encontramos en un momento de fuerte tendencia hacia la hibridación y el mestizaje, fruto del estudio, experiencia e inquietud creadora. Aunque el fenómeno hibridación no sería un hecho nuevo, pues se encuentra intrínseco desde los orígenes de este arte con los antecedentes expresivos, aunque se vería reforzado tras la etapa de la revalorización.

Además, la hibridación la hallaríamos en forma del concepto de 'bi-dancístico', como ya mencionamos, favoreciendo a una mayor formación, dominio técnico, corporal y expresivo e implicando una mayor estilización en el movimiento por parte del intérprete; como interrelación entre músicas e instrumentos diversos, por ejemplo, en Cuentos de azúcar (2018) de Eva Yerbabuena, -donde el flamenco y la música popular de Amami (Japón) a través de la voz de Anna Sato y el taiko de Kaoru Watanabe-, o en El amor brujo. Gitanería en un acto y dos cuadros (2019) de Israel Galván, -donde toma la música clásica de Manuel de Falla en la versión para piano-.

Por otro lado, en este período surgiría el modelo de ballet flamenco, teniendo su apogeo durante los comienzos y la segunda etapa de la teatralización flamenca, -con Encarnación López, Pilar López o Antonio Gades-, pues en la actualidad existe una vuelta al individualismo más próximo a lo que implica el flamenco 'tradicional', aunque hay excepciones. En el caso de Israel Galván, porque "no veo mi proyecto con un cuerpo de baile. Según el concepto de la obra, escojo a diferentes personas que para mí son súper importantes, pero no me veo como una compañía estándar" (2011).

No obstante, el flamenco es hijo de su tiempo. Un arte que va transformándose y actualizándose motivado por las necesidades intrínsecas de los artistas, así 
como por su contexto socioeconómico. De esta forma aparece el cuerpo danzante como un medio de comunicación, transmisión y reflexión de valores.

Sin embargo, a pesar de que el contexto condiciona a los creadores/intérpretes, no todos responden de la misma manera en cuanto a expresión y creación de movimientos y espectáculos, aunque sí existe una tendencia natural. Así, encontramos en la etapa actual de la teatralización creadores, como Adela Campallo, Farruquito, Belén López o María Juncal, que han actualizado su baile y estética flamenca personal sin profundizar e innovar en el campo escénico (escenografía, vestuario, iluminación, dramaturgia...), aunque sí en el musical, incorporando instrumentos y músicas no tradicionales al flamenco (piano, violín, flauta, batería o instrumentos indios). Esta suele ser una primera etapa o nivel de evolución del artista como creador.

Por otro lado, tenemos a creadores que han actualizado ya su baile y concepto de espectáculo, pudiendo ser: a) a partir de un lenguaje casi exclusivamente flamenco, como Sara Baras, Rafaela Carrasco o Manuel Liñán; b) a partir de un lenguaje híbrido (baile flamenco y contemporáneo, principalmente), como Eva Yerbabuena o Sara Cano; c) a partir de la colaboración con artistas de otras disciplinas dancísticas, como Eva Yerbabuena y Patrick de Bana en La Voz del silencio (2002) o El Huso de la memoria (2006) o María Pagés en Dunas (2009) con Sidi Larbi Cherkaouí; d) a partir de la colaboración con artistas de otros gremios, como Sara Baras con el tenor Josep Carreras en Baras-Carreras (2006) o Belén Maya en Habitaciones (2011) junto al actor y dramaturgo David Montero.

Y, por último, tendríamos la vertiente de creadores transgresores y vanguardistas que han desarrollado un concepto nuevo de espectáculo y de movimiento a partir de una formación y conocimientos previos en otras disciplinas, creando un lenguaje propio, personal, híbrido e innovador, pero teniendo como base el baile flamenco, como Belén Maya, Israel Galván, Andrés Marín o Rocío Molina. Aunque la artista Olga Pericet con La espina que quiso ser flor o la flor que soñó con ser bailaora (2017) o su último espectáculo Cuerpo infinito (2019) también transita por este camino de búsqueda y eliminación de barreras.

Estos artistas no buscan imitar o copiar los movimientos de otros, sino que más bien tratan de conectar y permeabilizar con sus propios universos artísticos intrínsecos en el intérprete. 
Creo que mi inspiración es un poco estar muy al corriente de todo lo que pasa y de lo que pasado. Es un todo. Si veo que en el mundo hay terremotos y hay víctimas le bailo a eso, si en el mundo hay violencia, yo bailo en contra de eso, no me quiero quedar siempre en la partitura del flamenco ni en el tópico.

(Galván 2011)

Surge así la nueva clasificación del 'baile flamenco contemporáneo', relacionado, a su vez, con la corriente del 'nuevo flamenco'. Una vertiente formada por creadores que a través de la búsqueda en su cuerpo y sus diversas posibilidades, dinámicas, formas, sonidos, amplían su abanico creativo e interpretativo gracias a su proximidad con otras danzas, artistas (Teresa Nieto, Antonio Ruz o Akram Khan) y a partir de su autoconocimiento que surge siempre desde el arraigo en la tradición, danzando desde una gran libertad en la obra o 'laboratorio', en palabras de Galván. Libertad del cuerpo creativo y de la mente creativa sin censura por parte de miedos o de la tradición familiar o artística.

Profundizando ya en la figura de Israel Galván (1973), Premio Nacional de Danza en 2005, hay que decir que se trata de un bailaor y coreógrafo con una necesidad de búsqueda y trabajo constante: "veo mi cuerpo como una sinfonía de movimientos, y todavía no suena como yo quiero, por eso me centro más en mí mismo" (Galván en Barón \& Galván 2009, 23).

A partir de su trabajo en la Compañía Andaluza de Danza de Mario Maya, en 1998 creó su propia compañía llevando a cabo diferentes espectáculos que han supuesto un desarrollo y evolución para el artista hasta convertirse en lo que es hoy. Así, encontramos en su repertorio las obras: ¡Mira! / Los zapatos rojos (1998), La metamorfosis (2000), Galvánicas (2002), Arena (2004), La edad de oro (2005), Tábula rasa (2006), Solo (2007) -inspirado en Vicente Escudero y su baile sin música-, El final de este estado de cosas, Redux (2008), La curva (2010) -inspirado de nuevo en Vicente Escudero y su espectáculo La courbe (1924)-, Lo real / Le réel / The real (2012) -donde reflexiona sobre el holocausto gitano en la época de nazi, acompañado de Belén Maya e Isabel Bayón-, Torobaka (2014) -obra en la que se une al artista Akram Khan creando un proyecto híbrido de movimientos (danza kathak y baile flamenco) y con sonidos, voces e instrumentos percusivos de India (kanjira, dholak, ghungroo y tarang)-, FLA.CO.MEN (2014), La fiesta (2017) -obra en la que profundizaremos a continuación-, y El amor brujo: Gitanería en un acto y dos cuadros (2019). Aunque también crearía para espectáculos de otras bailaoras, 
como en Romnia (2015) de Belén Maya o Dju-dju (2016) para Isabel Bayón, además de colaborar con músicos y cineastas.

Seriedad. Transgresión. Ironía. Saber estar. Dominio del espacio. Referencias pictóricas y literarias. Control rítmico. Geometrismo racional. Poso técnico. Cultura del baile. Vasos comunicantes con el toreo. Plástica actual. Voluntad contestataria. Herencia de Escudero. Pasión por el negro. Israel Galván un bailaor, joven en edad, pueda introducir este arte en las corrientes contemporáneas del siglo XXI, sin romperlo. . . Galván ha hecho simplemente algo sencillo: mirar en el interior del flamenco, y ha encontrado su piedra Rosetta. El ya está en su universo, el resto sigue buscando.

(Salas 2005)

\section{LA FIESTA DE ISRAEL GALVÁN}

"Todos los trabajos que he hecho me han marcado el cuerpo, ya no puedo bailar como antes, me lo han lesionado de una manera artística” (Galván 2011). De esta forma, tras tres trabajos claves como son Torobaka, -donde desarrolla junto a Akram Khan una hibridación del flamenco con sonidos y músicas orientales y la danza kathak-, Solo, -donde profundiza en las sonoridades a partir de la no música-, y FLA.CO.MEN, -donde trabaja con concepto de la alegría y frenesí-, se nos presenta La fiesta (2017), como un nuevo punto de inflexión, en el que nutrido por sus diferentes experiencias crea una obra híbrida y vanguardista a nivel musical, dancístico y de concepción de espectáculo, acompañado de Eloísa Cantón, Ramón Martínez, El Junco, La Uchi, Minako Seki, Niño de Elche, Emilio Caracafé, Alejandro Rojas-Marcos y Alia Sellami.

Con el escenario desnudo y rompiendo la cuarta pared con el espectador, profundiza en el concepto que representa la fiesta desde la más absoluta libertad, con sus detalles, gestos, movimientos, sonidos y energías. Por lo que, el resultado obtenido es una 'comunión' entre los intérpretes donde, como actores, contribuyen al texto y desarrollo de la obra en favor del diálogo, herencia de Mario Maya. Todo esto envuelto en sonidos guturales, jaleos, onomatopeyas, fragmentos de canciones en francés, inglés y alemán, risas, llantos, gritos, palmas sonoras y mudas, nudillos sobre la tarima o los dientes, sonidos con las monedas, las piedras o las chapas, y acompañados de instrumentos como 
el clavicordio, armonium, guitarra, violín, una pata de jamón, -que igual hace de guitarra que de violonchello-, o ghungroo.
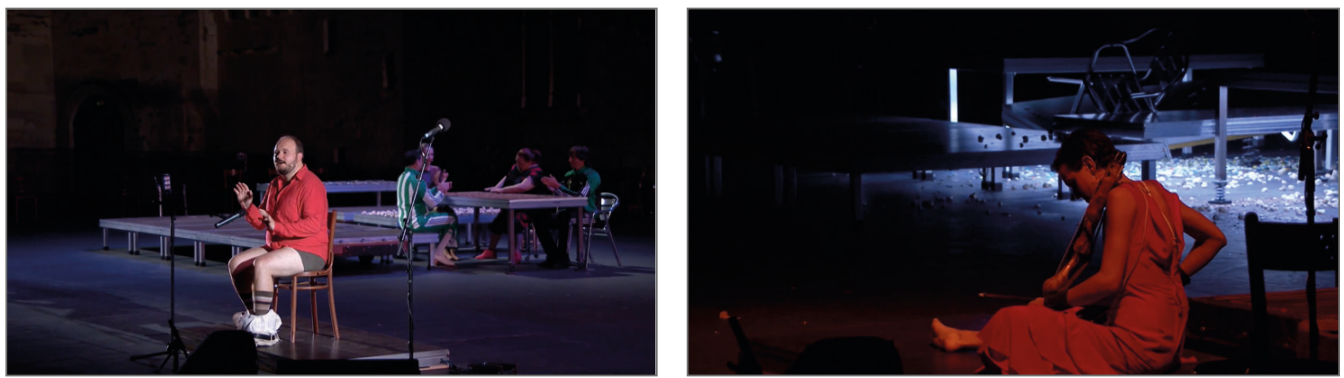

Capturas de imágenes de La Fiesta (2017) de Israel Galván

A nivel dancístico, vemos cómo Galván profundiza en su lenguaje a partir del flamenco, buscando nuevas maneras de expresarse, dotando a los movimientos de gran simbolismo, como cuando se fustiga en el momento de la misa a compás de seguiriya. Asimismo, explora el movimiento del cuerpo en el suelo buscando formas diferentes de interpretar unas 'patas' por bulerías, zapateando, marcando y rematando, arrastrándose, sobre las rodillas o a cuatro patas.

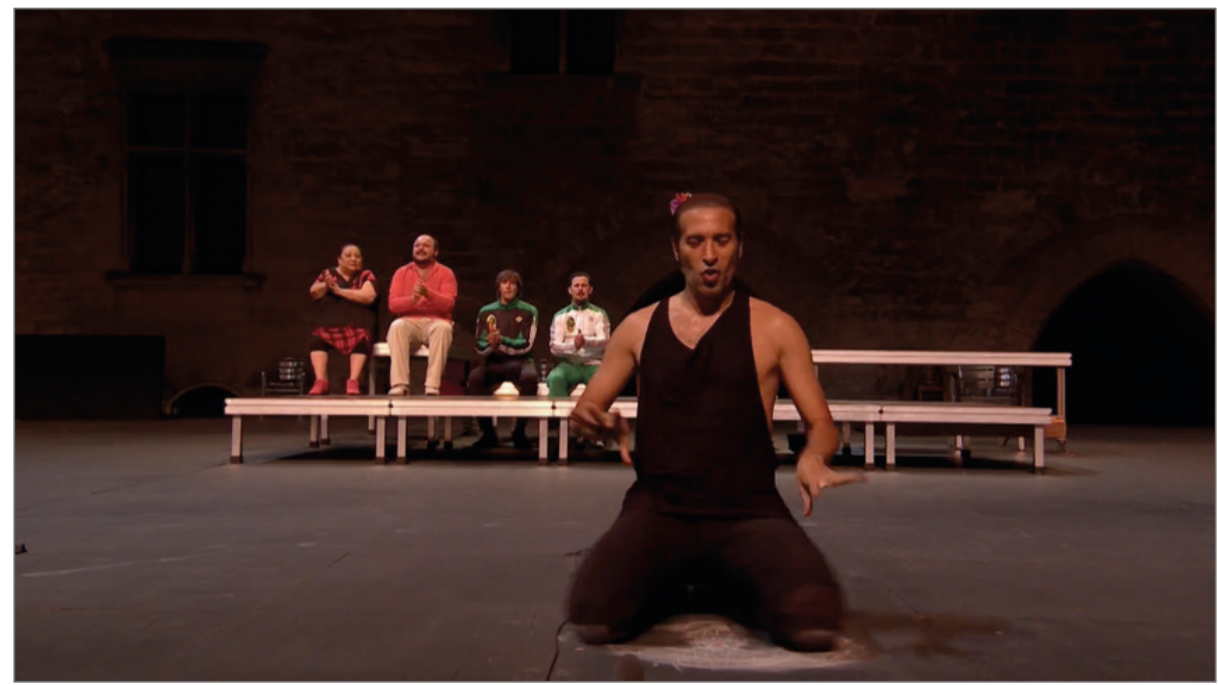

Es importante tener en cuenta que para Galván ser bailaor implica ser músico, por lo que busca la musicalidad y la rítmica en todos los elementos internos 
y externos al artista, creando una base musical sobre la que bailar, moverse y configurar un espectáculo, apoyado por elementos escénicos como sillas, tarimas (como escenarios), un silbato, la calabaza como máscara y como recipiente para las palomitas y gusanitos, con un vestuario con los chándales del Betis o Galván con rodilleras, de negro y en un momento recurre a una especie de blusa con capucha que la emplea como velo. La iluminación de Carlos Marquerie también juega con el papel importante creando espacio y tiempo, en un momento concreto aparecen los colores de Betis de fondo. Por tanto, La fiesta es un viaje por los diferentes estados de una fiesta, donde el papel de la música y el oído se privilegia sobre la vista.

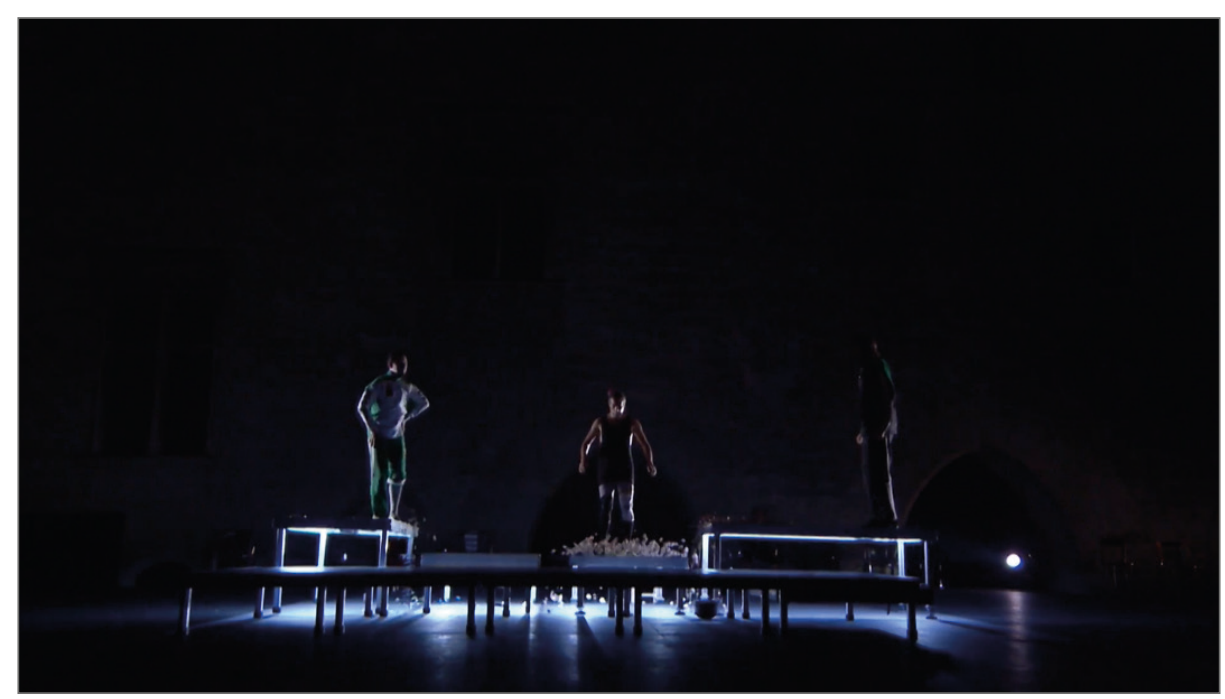

\section{CONCLUSIONES}

Para concluir, hay que recalcar que el baile flamenco se trata de una manifestación artística cuyos pasos, ritmos y movimientos poseen una gran fuente de riqueza expresiva e interpretativa. Un arte de técnica sólida, que facilita la necesidad por parte de los artistas de seguir formándose a través de la búsqueda de personalidad, genio y creatividad, lo que los lleva a introducirse en el campo de otras disciplinas dancísticas y artísticas.

Todo ello en un momento de la globalización, de fuertes flujos culturales y con una importante herencia de creadores de anteriores generaciones de la teatralización, quienes profundizaron en el concepto de obra de arte total, 
cobrando gran importancia elementos como la iluminación, narrativa, escenografía, vestuario, danza y música. Así, con el contexto del fenómeno del Nuevo Flamenco, surge el Baile Flamenco Contemporáneo de artistas como Israel Galván, donde el fenómeno hibridación en su danza, -con una difuminación de las diferenciaciones de género establecidas antaño y una retroalimentación de diferentes estilos dancísticos-, y en su música, -con sonidos y cantes de otros lugares (inglés, francés, alemán, hindú)-, se encuentra muy presente a través de su lenguaje innovador de búsqueda introspectiva.

No obstante, la innovación en el terreno sonoro también la encontramos en obras de artistas como Rocío Molina, Daniel Doña, Olga Pericet o Belén Maya. Vemos cómo en Bosque Ardora introduce Molina instrumentos no tradicionales al flamenco (batería, trombón y bajo eléctrico), aparece el elemento electrónico y loops, por ejemplo, en Afectos de Molina, la presencia del micrófono para el bailarín en Hábitat de Daniel Doña, con sonidos que recuerdan al konnakol, la combinación de músicas y sonidos en directo con pregrabados en Petisa Loca de Sara Calero. El concepto de fiesta también lo vemos abordado en Caída del Cielo de Molina, entendido desde un sentido trágico y dramático, o en Tr3s de Belén Maya.

Por tanto, no sabemos si el baile flamenco se verá redefinido por un lenguaje más híbrido, pero lo que sí es cierto, es que existen diferentes espacios para la representación de este arte, encontrando las peñas o tablaos como ese lugar para el flamenco más 'tradicional', aunque actualizado, mientras que los teatros y espacios alternativos favorecerán a la innovaciones, transgresiones e hibridaciones.

\section{Referencias bibliográficas}

Álvarez Caballero, Ángel. 1998. El baile flamenco. Madrid: Alianza

Barón, Javier [Francisco Javier Álvarez Rico] \& Israel Galván [de los Reyes]. 2009. "La raíz y la savia nueva". Entrevistas por Aida Rodríguez Agraso. La Nueva Alboreá 11: 18-23. http:// www.juntadeandalucia.es/cultura/centroandaluzflamenco/NuevaAlborea/Revistas/Alborea11.pdf

Cabrera Fructuoso, María. 2019. "Baile flamenco: Hibridación hasta la actualidad; Mercado, enseñanza y nuevas necesidades expresivas". Tesis Univ. Rey Juan Carlos de Madrid. http://hdl.handle.net/10115/17511

Galván [de los Reyes], Israel. 2011. "Entrevista a Israel Galván, bailaor de flamenco". Por Ana Martos. Culturamas (blog), 24 feb. http://www.culturamas.es/blog/2011102/24/entrevista-a-israel-galvan-bailaor-de-flamenco/ 
García Peinazo, Diego. 2013. "Músicas de la ciudad imaginada. Modernidad, identidad y europeísmo en el videoclip y spot de rock andaluz para la campaña Córdoba 2016: Ciudad Europea de la Cultura". Cuadernos de Etnomusicología 3: 6-28

Guerra y Sánchez, Ramiro. 1989. Teatralización del folklore y otros ensayos. La Habana: Letras Cubanas

Martínez Berriel, Sagrario. 2008. "La música en la ciudad sin límites: Transformaciones urbanas y musicales en la ciudad global". En Música, ciudades, redes: Creación musical e interacción social, actas del X Congreso de la Sociedad Ibérica de Etnomusicología. Sabadell: SIBE-Sociedad de Etnomusicología

Salas, Roger. 2005. "Bendita heterodoxia”. El País, 22 jul. http://elpais.com/diario/2005/07/22/ espectaculos/1121983209_850215.html

Sedeño Valdellós, Ana María. 2003. "Realización audiovisual y creación de sentido en la música: El caso del videoclip musical de Nuevo Flamenco". Tesis Univ. Málaga. https://riuma. uma.es/xmlui/handle/10630/2540

Steingress, Gerhard. 2004. "La hibridación transcultural como clave de la formación del Nuevo Flamenco (aspectos historiosociológicos, analíticos y comparativos)". Trans Revista Transcultural de Música 8. http://www.redalyc.org/articulo.oa?id=82200812

Steingress, Gerhard. 2013. "La creación del espacio socio-cultural como marco de la performance híbrida: El género del canto y baile andaluz en los teatros de Buenos Aires y Montevideo (1832-1864)". Trans Revista Transcultural de Música 17: 1-44. http://hdl.handle. net/11441/17044

\section{Notas}

${ }^{1}$ Capturas de imágenes de La Fiesta (2017) de Israel Galván en https://www.youtube.com/watch? $v=$ Bwce Ji6V1wk\&t=22s 